\title{
MEMBANGUN APLIKASI USAHA SIMPAN PINJAM KOPERASI PADA PT. LOTTE SHOPPING INDONESIA
}

\author{
Tatang Suhidin ${ }^{1}$, Lukman $^{2}$, Natalia Tri Astuti ${ }^{3}$ \\ ${ }^{1,2,3}$ Teknik Informatika, Fakultas Ilmu Komputer, Universitas Indraprasta PGRI Jakarta \\ Jalan Raya Tengah No 80, Kelurahan Gedong, Pasar Rebo, Jakarta Timur \\ 1.
}

\begin{abstract}
ABSTRAK
Permasalahan yang terdapat pada Koperasi PT. Lotte Shopping Indonesia adalah sulitnya mengetahui data anggota, data simpanan, data peminjaman dan data pembayaran angsuran serta proses pencatatan baik itu data anggota, data simpan dan data pinjaman memakan waktu lama, karena dalam melakukan pencatatan dan pengolahan data yang dilakukan dengan cara ditulis dan diarsipkan dalam buku atau dokumen koperasi bisa memakan waktu hingga berjam-jam. Tujuan membangun aplikasi usaha koperasi simpan pinjam ini untuk memudahkan admin dalam memproses pengolahan data yang ada saat ini serta memperkecil kemungkinan hilangnya data dan terjadinya duplikasi data, karena data tidak dicatat lagi dibuku tetapi data disimpan dalam sebuah database. Perangkat aplikasi yang telah dibuat dengan bahasa pemrograman Java NetBeans 8.0.2 dan penyimpanan data pada database MySQL dapat memberikan kelancaran dalam proses menginput dan penyimpanan data-data serta laporan-laporan yang diberikan kepada Pimpinan. Dengan menggunakan metode penelitian Research and Development menjadikan penelitian ini sesuai dengan yang diharapkan. Hasil dari penelitian ini menciptakan suatu sistem aplikasi usaha koperasi simpan pinjam yang dapat memudahkan pihak koperasi dalam proses pendataan data anggota, data simpanan, data pinjaman serta data pembayaran angsuran yang lebih efisien.
\end{abstract}

Kata Kunci: Aplikasi, Simpan Pinjam, Koperasi, Desktop

\begin{abstract}
The problems that exist in the Cooperative PT. Lotte Shopping Indonesia is difficult to find out member data, savings data, loan data and installment payment data as well as the recording process both member data, saving data and loan data takes a long time, because in recording and processing data it is done by writing and filing in cooperative books or documents can take up to hours. The purpose of building this savings and loan cooperative business application is to make it easier for admins to process existing data processing and minimize the possibility of data loss and data duplication, because the data is no longer recorded in the book but the data is stored in a database. Application devices that have been created with the Java NetBeans 8.0.2 programming language and data storage in the MySQL database can provide smoothness in the process of inputting and storing data and reports given to the leadership. By using the Research and Development research method, this research is as expected. The results of this study create a savings and loan cooperative business application system that can facilitate the cooperative in the process of collecting member data, savings data, loan data and installment payment data more efficiently.
\end{abstract}

Key Word: Application, Saving and Loan, Cooperative, Desktop

\section{PENDAHULUAN}

Koperasi berasal dari kata: Co dan operation, Co berarti bersama dan operation berarti kegiatan/pekerjaan. Dari dua kata tersebut pengertian dasarnya menjadi "Bersama-sama melakukan kegiatan atau pekerjaan untuk mencapai suatu tujuan bersama, secara demokratis, terbuka dan sukarela (Subyantoro, 2015). Ciri utama koperasi adalah kerja sama anggota dengan tujuan untuk mencapai kesejahteraan hidup bersama. Terdapat bermacam-macam definisi koperasi dan jika diteliti secara seksama, maka tampak bahwa definisi itu berkembang sejalan dengan perkembangan jaman (Samsudin, Abdurahman, \& Abdullah, 2019).

Koperasi Simpan Pinjam Karyawan PT. Lotte Shopping Indonesia merupakan balai usaha 
mandiri terpadu yakni lembaga usaha yang mengembangkan aspek-aspek produksi dan investasi untuk meningkatkan kualitas kegiatan ekonomi dalam sekala kecil dan menengah (Widiati, 2017). Koperasi Simpan Pinjam Karyawan PT. Lotte Shopping Indonesia sebagai koperasi syariah yakni lembaga ekonomi yang berfungsi untuk menarik, mengelola, dan menyalurkan dana dari oleh dan untuk kita. Oleh karena itu Koperasi ini dapat disebut sebagai swadaya ekonomi umat yang dibentuk, dari, oleh dan untuk kita (Astuti \& Devitra, 2017).

Sebagai lembaga bisnis, Koperasi Simpan Pinjam Karyawan PT. Lotte Shopping Indonesia lebih mengembangkan usahanya pada sektor keuangan, yakni simpan pinjam, produk pinjaman berupa pembiayaan. Pembiayaan yang ada pada Koperasi di PT. Lotte Shopping Indonesia yaitu pembiayaan Mudharabah (Fuad, 2015). Dalam simpan pinjam Koperasi di PT. Lotte Shopping Indonesia masih ditemui beberapa permasalahan yang memperlambat kinerja Koperasi dalam penginputan administrasi keanggotaan simpan pinjam, penyimpanan data fisik yang masih belum tertata secara rapih dan teratur, hal tersebut dapat dilihat dari bagaimana proses transaksi simpan, pinjam, dan pembayaran angsuran (Wati \& Siahaan, 2017). Penginputan tersebut masih menggunakan sistem yang belum terkomputerisasi sehingga sering terjadi kesalahan pencatatan, arsip yang sulit dicari dan masalah lainnya. Minimnya jumlah pengolahan koperasi juga menjadi salah satu faktor yang dapat memperlambat kinerja penginputan administrasi keanggotaan.

Dengan permasalahan tersebut, perlu ada nya suatu sistem yang terkomputerisasi dalam penyelesaiannya. Sistem adalah sekelompok unsur yang erat hubungannya satu dengan yang lain, yang berfungsi bersama-sama untuk mencapai tujuan (Sutabri, 2012). Sistem merupakan suatu kumpulan dari komponenkomponen yang membentuk satu kesatuan (Tyoso, 2016). Pembangunan sistem adalah sekumpulan aktivitas yang menggambarkan secara rinci bagaimana sistem akan berjalan. Hal itu bertujuan untuk menghasilkan produk perangkat lunak yang sesuai dengan kebutuhan user (Satzinger, J. W., Jackson, R. B., Burd, n.d.).
Diharapkan dengan adanya suatu sistem informasi dapat menangani permasalahan yang ada di perusahaan tersebut. Sistem adalah setiap sesuatu terdiri dari obyek-obyek, atau unsur-unsur, atau komponen-komponen yang bertata kaitan dan bertata hubungan satu sama lain, sedemikian rupa sehingga unsur-unsur tersebut merupakan satu kesatuan pemrosesan atau pengolahan yang tertentu (Prasojo, 2011).

Aplikasi ini dapat memudahkan pekerjaan Admin dalam melaksanakan pembuatan laporan dan dapat memudahkan perusahaan dalam pendataan koperasi simpan pinjam di PT. Lotte Shooping Indonesia.

\section{METODE PENELITIAN}

Penulis menggunakan metode Research and Development dalam penyelesaian penelitian ini. (Sugiyono, 2016). Dalam pelaksanaan R\&D, ada beberapa metode yang digunakan yaitu metode deskriptif, evaluatif dan eksperimental. Metode penelitian deskriptif digunakan dalam penelitian awal untuk menghimpun data tentang kondisi yang ada yaitu penulis membutuhkan data-data yang dapat menunjang tercipta nya suatu sistem informasi koperasi simpan pinjam seperti data anggota, data simpanan, data pencairan, data pinjaman dan data pembayaran angsuran terdahulu yang masih tersimpan secara manual didalam buku besar.

Metode evaluatif digunakan untuk mengevaluasi proses ujicoba pengembangan suatu produk, dalam proses ini penulis melakukan ujicoba terhadap suatu sistem yang telah dirancang agar tidak ada terjadi kesalahan dalam proses penginputan data serta pelaporan bulanan kepada pimpinan. Dan metode eksperimen digunakan untuk menguji keampuhan dari produk yang dihasilkan, dalam proses yang terakhir ini perlu dilakukan pengujian akhir yang diharapkan bahwa sistem yang dirancang oleh penulis dapat berjalan dengan baik dan sesuai dengan kebutuhan dan terfokus pada proses simpan pinjam pada koperasi PT. Lotte Shopping Indonesia. Meskipun sudah diperoleh produk yang lebih sempurna, tetapi uji coba dan penyempurnaan produk masih perlu dilakukan sekali lagi. Hal ini dilakukan agar produk yang dikembangkan memenuhi standar 
tertentu. Oleh karena itu target populasinya pun harus disesuaikan. Uji coba dan penyempurnaan pada tahap produk awal masih difokuskan kepada pengembangan dan penyempurnaan materi produk, belum memperhatikan kelayakan dalam konteks populasi. Kelayakan populasi dilakukan dalam uji coba dan penyempurnaan produk yang telah disempurnakan.

\section{HASIL DAN PEMBAHASAN}

\section{Alternatif Penyelesaian Masalah}

Pemecahan masalah merupakan suatu tindakan yang harus dilaksanakan dalam menghadapi permasalahan yang ada pada PT. Lotte Shooping Indonesia, berdasarkan hasil Analisis dan uraian umum tentang sistem yang sedang berjalan maka harus dicari alternatif penyelesaian masalah agar dapat dilakukan perbaikan-perbaikan ke arah positif sehingga dapat menunjang koperasi dalam peningkatan kerja. Berikut uraian dari penyelesaian masalah yang diharapkan:

1. Perlu adanya aplikasi sistem informasi yang terkomputerisasi sehingga dapat memperbaiki kinerja PT. Lotte Shooping Indonesia khususnya dalam bagian koperasi simpan pinjam karyawan, peminjaman dana dan pembayaran.

2. Proses pengolahan data pada admin lebih efisien, tepat dan akurat.

3. Dalam proses penginputan data dari anggota yang hendak melakukan peminjaman tidak lagi menggunakan sistem manual namun sudah terkomputerisasi.

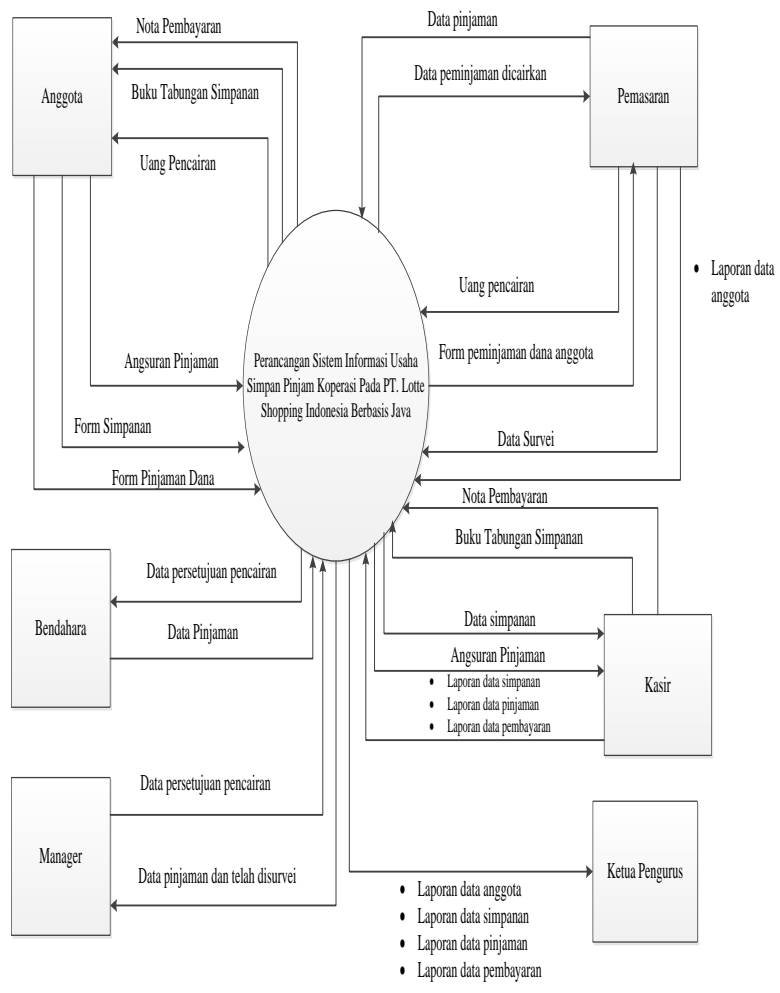

Gambar 1. Diagram Konteks

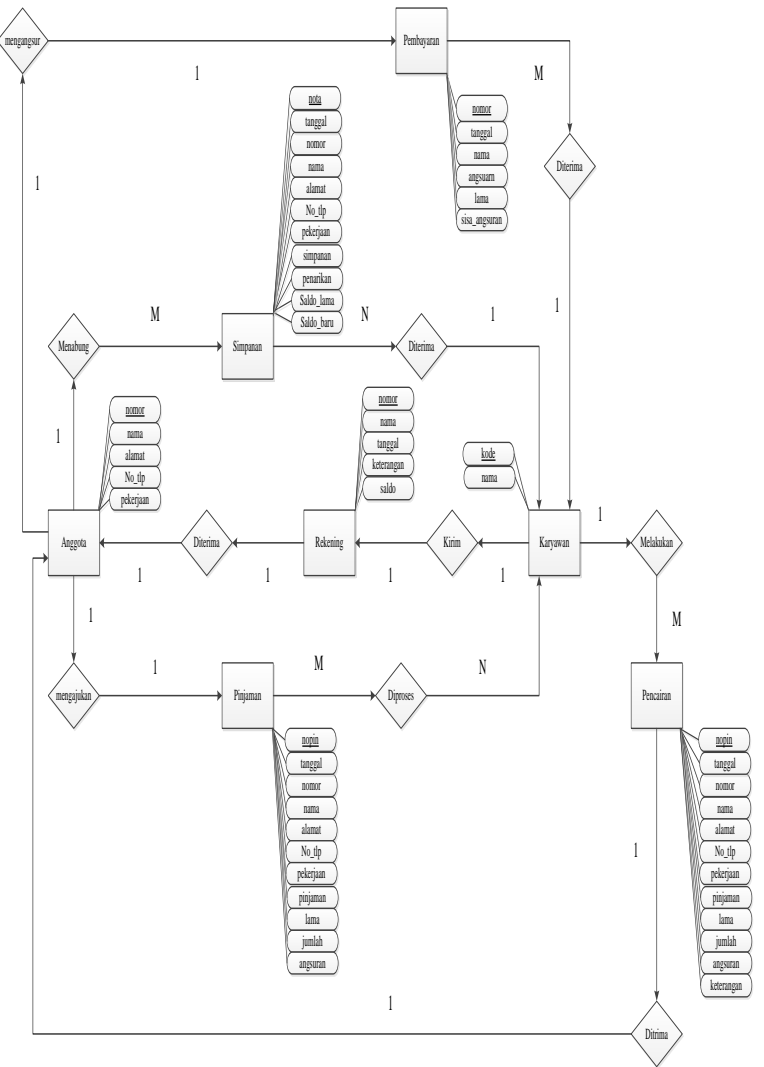

Gambar 2. ERD (Entity Relationship Diagram) 
Berikut adalah tampilan layar dan hasil pengujian pada software program yang telah di buat dengan bahasa pemrograman Java.

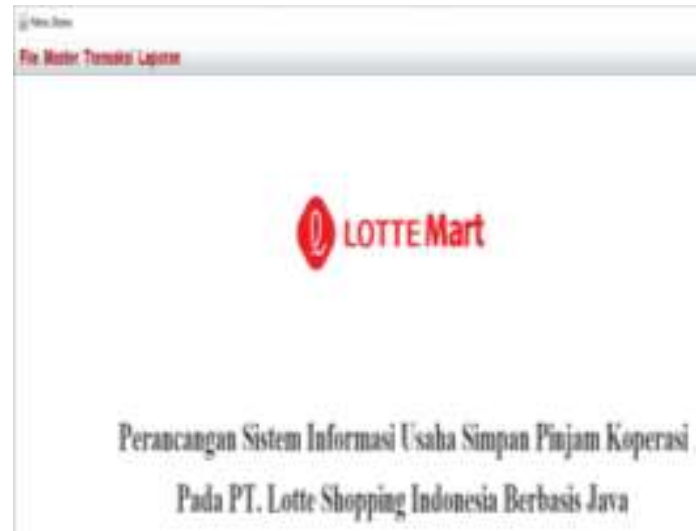

\section{Gambar 3. Form Menu Utama}

Layar di atas menampilkan tampilan Menu Utama pada Sistem Informasi Koperasi Simpan Pinjam Karyawan di PT. Lotte Shopping Indonesia. Pada layar utama tersedia menu bar yang terdiri dari master data yang digunakan untuk memasukkan data yang berkaitan dengan data anggota, data simpanan, data pinjaman, data pembayaran dan laporan-laporan.

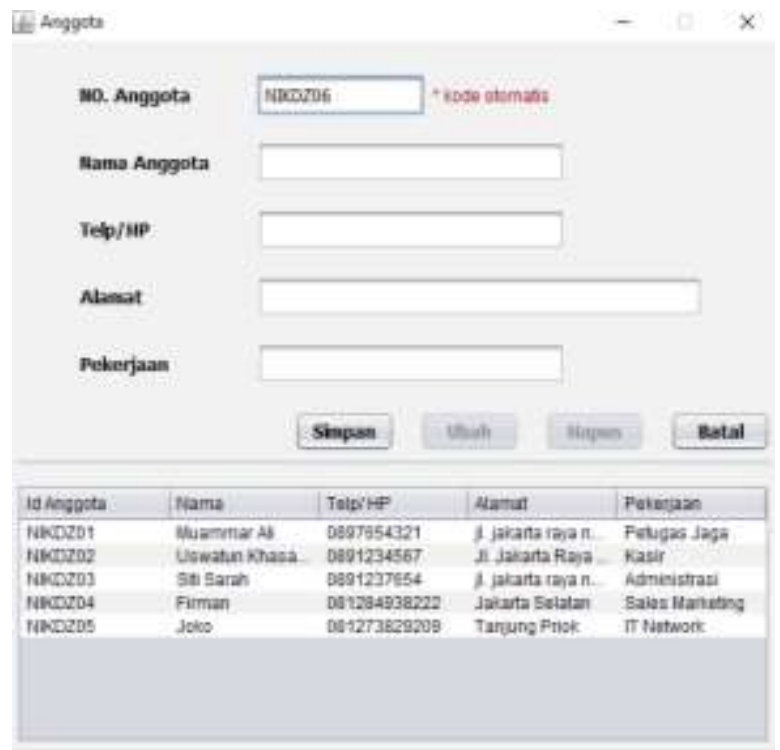

Gambar 4. Form Data Anggota

Layar di atas menampilkan tampilan form data anggota. Pada layar form data anggota untuk meng-input data barang yang terdiri dari ID
Anggota, Nama Anggota, Telp, Alamat dan Pekerjaan.

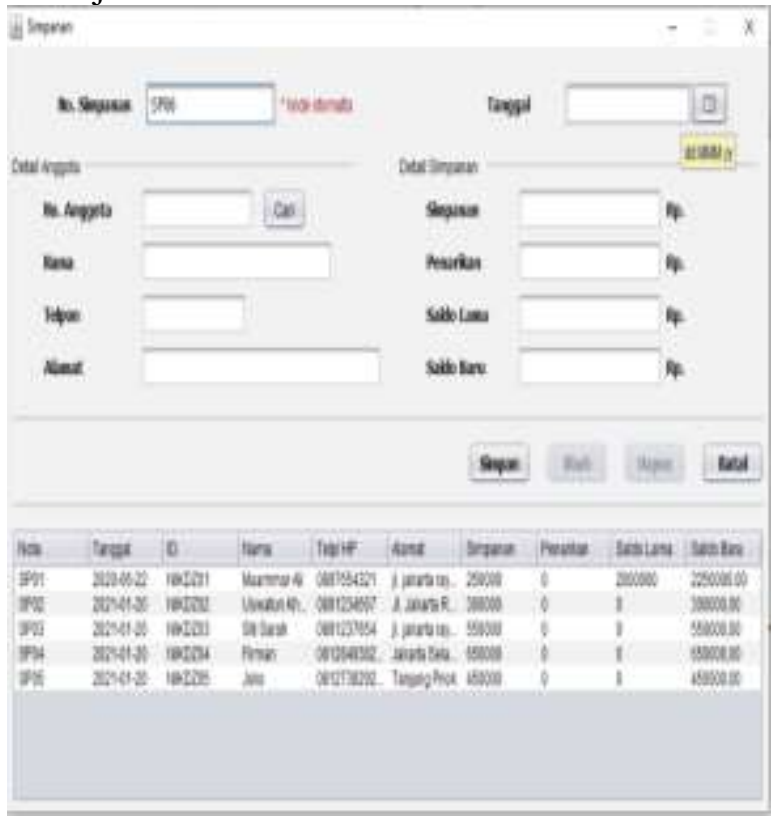

Gambar 5. Form Data Simpanan

Layar di atas menampilkan tampilan form data simpanan. Pada layar form data simpanan untuk meng-input data gudang yang terdiri dari No Simpanan, Tgl Simpanan, No Anggota, Nama Anggota, No Telp, Alamat, Simpanan, Penarikan, Saldo Lama dan Saldo Baru.

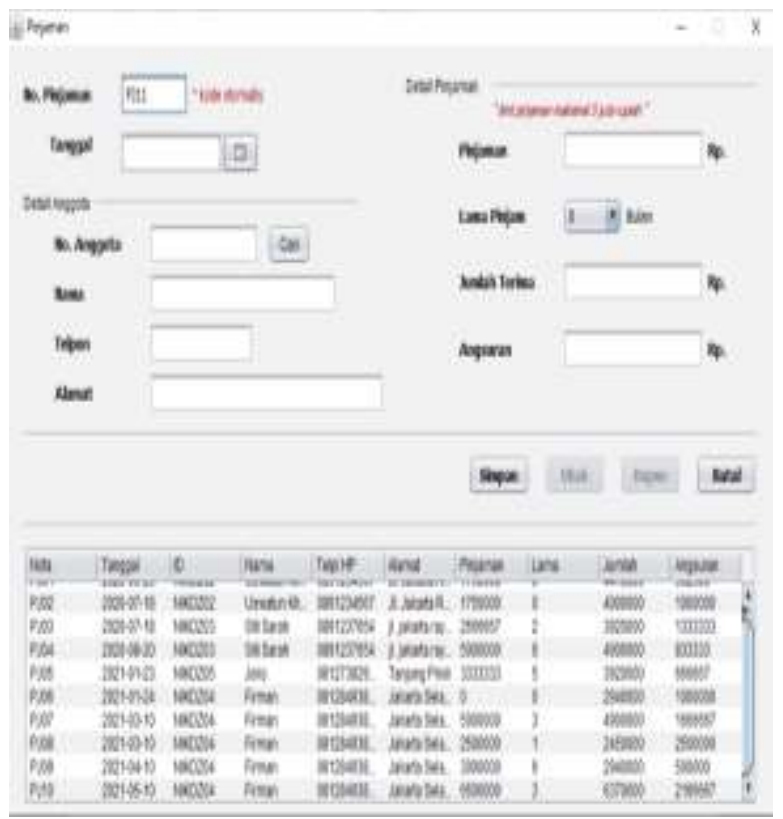

Gambar 6. Data Form Data Pinjaman

Layar di atas menampilkan tampilan form data pinjaman. Pada layar form data pinjaman untuk 
meng-input data pinjaman yang terdiri dari No Pinjaman, Tgl Pinjaman, No Anggota, Nama Anggota, No Telp, Alamat, Pinjmana, Lama Pinjaman, Jumlah Terima dan Angsuran.

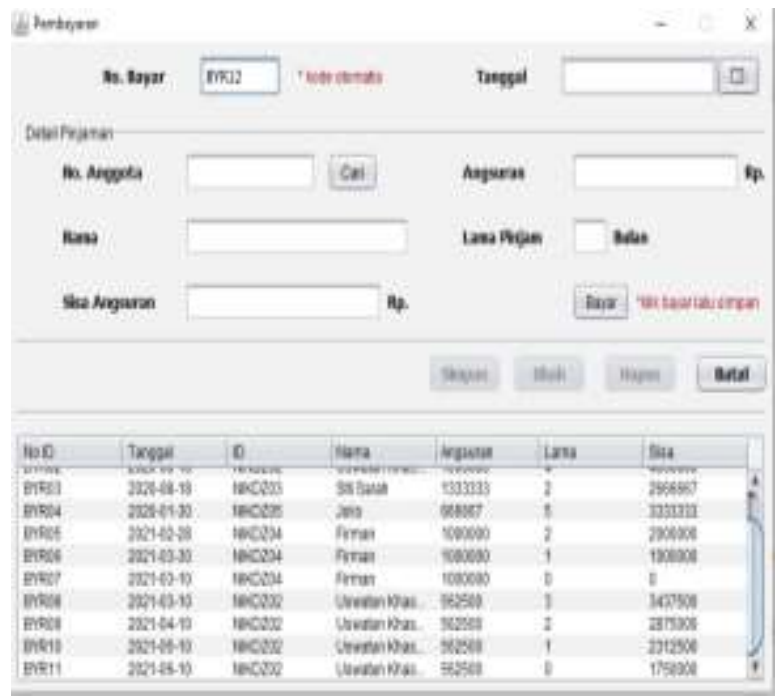

Gambar 7. Laporan Data Pembayaran

Layar di atas menampilkan tampilan form data pembayaran. Pada layar form data pembayaran untuk meng-input data pembayaran yang terdiri dari No Bayar, Tgl Bayar, No Anggota, Nama Anggota, Sisa Angsuran, Angsuran dan Lama Pinjam.

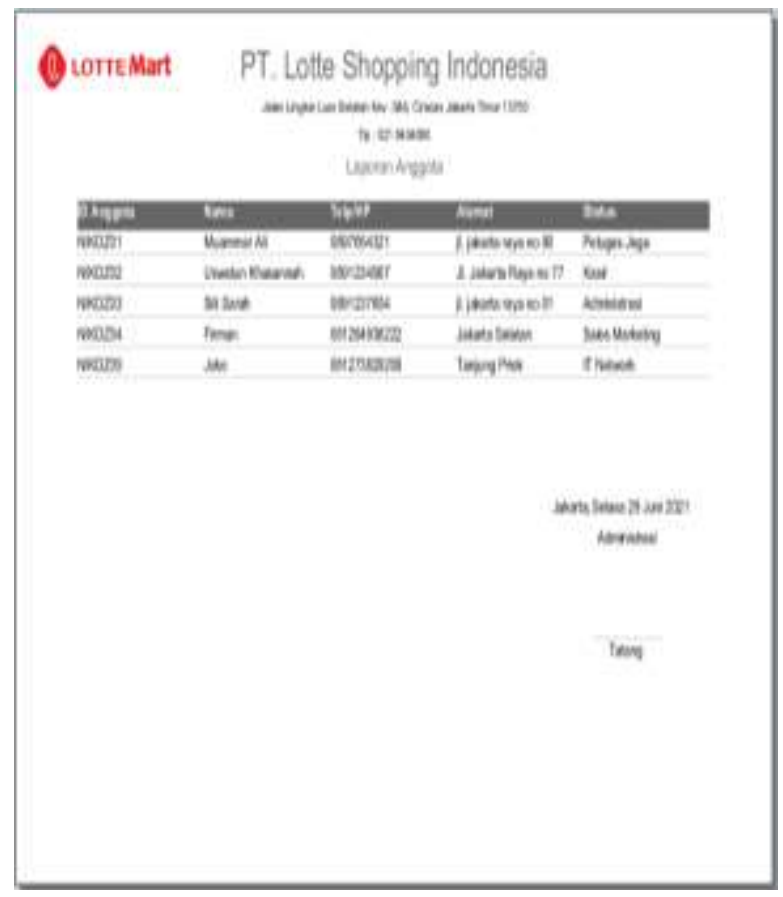

Gambar 8. Laporan Data Anggota
Layar di atas menampilkan tampilan form laporan data anggota. Pada layar form data anggota masuk digunakan untuk mengecek laporan data anggota masuk terdiri ID Anggota, Nama Anggota, No Telp, Alamat, dan Pekerjaan.

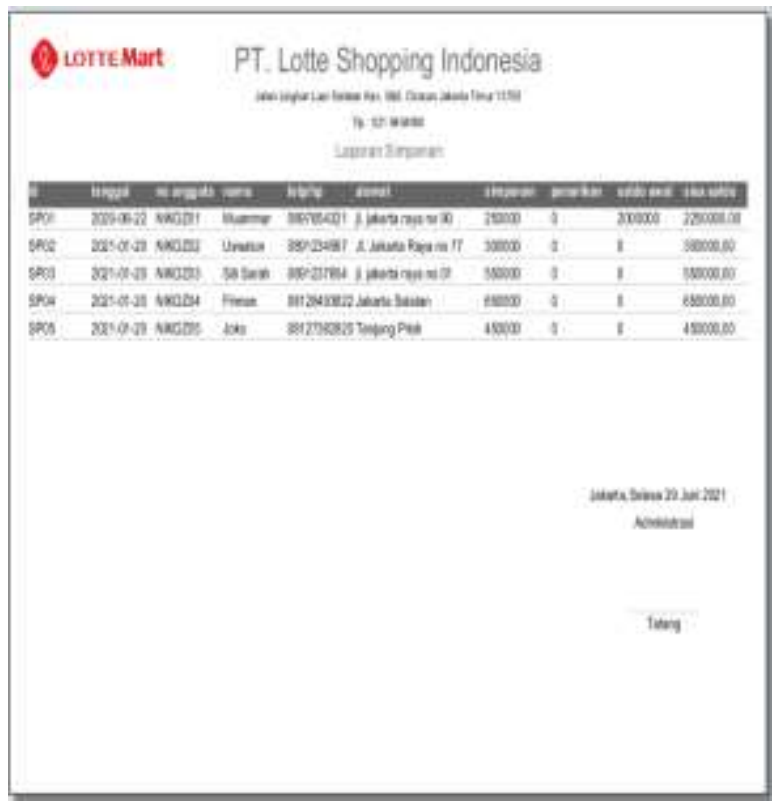

Gambar 9. Laporan Data Simpanan

Layar di atas menampilkan tampilan form laporan data simpanan. Pada layar form data simpanan digunakan untuk mengecek laporan data simpanan terdiri No Simpanan, Tgl Simpanan, No Anggota, Nama Anggota, No Telp, Alamat, Simpanan, Penarikan, Saldo Awal dan Sisa Saldo.

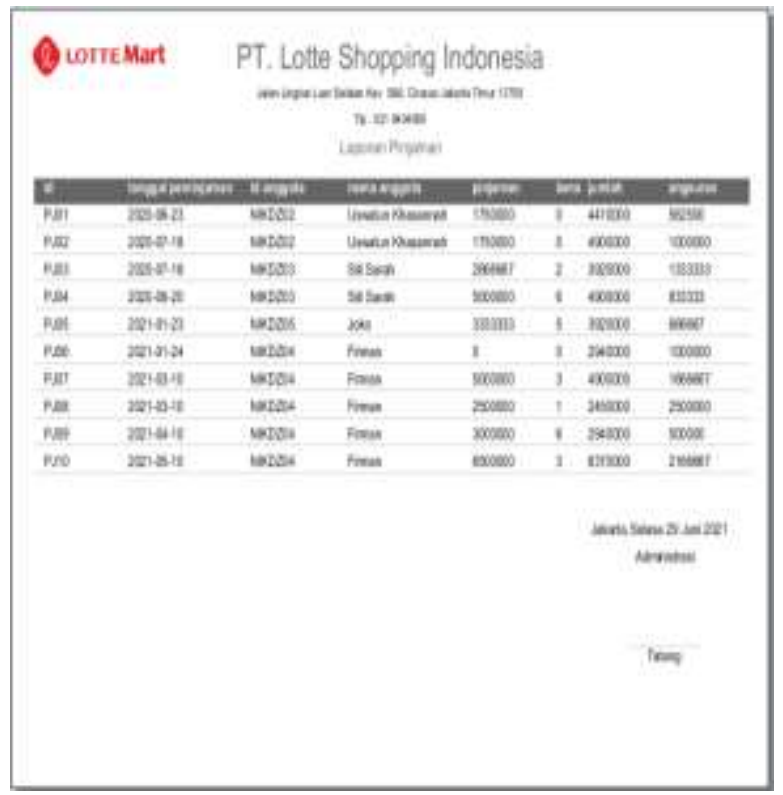

Gambar 10. Laporan Data Pinjaman

175 | Membangun Aplikasi Usaha Simpan Pinjam Koperasi pada PT. Lotte Shopping Indonesia 
Layar di atas menampilkan tampilan form laporan data pinjaman. Pada layar form data pinjaman digunakan untuk mengecek laporan data pinjaman terdiri No Pinjaman, Tgl Pinjaman, No Anggota, Nama Anggota, No Telp, Alamat, Pinjmana, Lama Pinjaman, Jumlah Terima dan Angsuran.

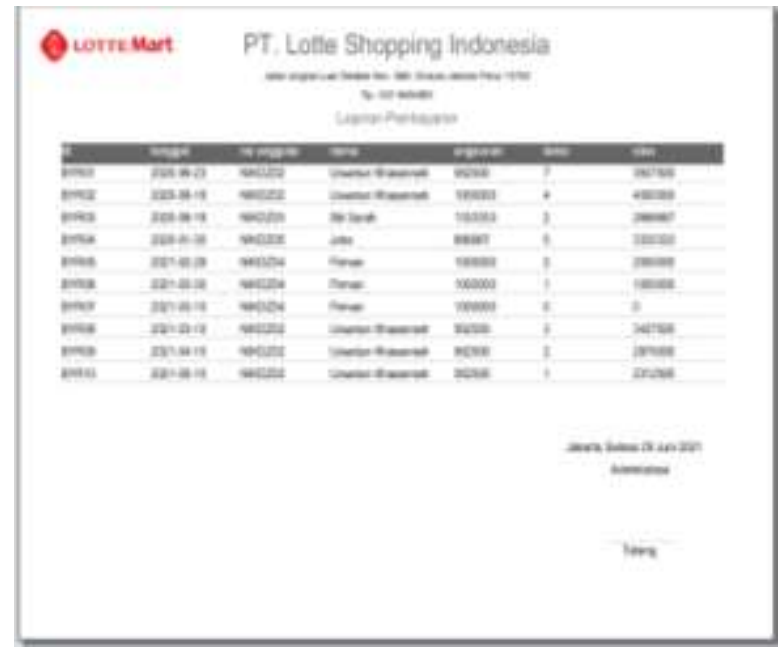

Gambar 11. Laporan Data Pembayaran

Layar di atas menampilkan tampilan form laporan data pembayaran. Pada layar form data pembayaran digunakan untuk mengecek laporan data pembayaran terdiri No Bayar, Tgl Bayar, No Anggota, Nama Anggota, Sisa Angsuran, Angsuran dan Lama Pinjam.

\section{SIMPULAN DAN SARAN}

Sistem yang dirancang dapat memperkecil kemungkinan hilangnya data dan terjadinya duplikasi data, karena data tidak dicatat lagi dibuku tetapi data disimpan dalam sebuah database. Aplikasi memiliki menu untuk mengelola data administrasi anggota koperasi, data simpan pinjam koperasi, data angsuran pinjaman, angsuran denda pinjaman, dan laporanlaporan.

Hasil ujicoba aplikasi usaha simpan pinjam koperasi PT. Lotte Shopping Indonesia ini memiliki efektivitas yang baik sehingga dapat mempercepat kinerja karyawan.

Saran untuk perusahaan, sebaiknya seluruh pihak yang terkait dalam sistem harus diberikan penjelasan dengan baik terlebih dahulu mengenai proses kerja aplikasi yang diterapkan sehingga tidak terjadi kekeliruan. Serta perlu dilakukan pelatihan penggunaan aplikasi tersebut terhadap pengurus yang terlibat dalam Aplikasi Koperasi Simpan Pinjam Karyawan ini, agar pengurus dapat mengetahui dan memahami cara kerja aplikasi yang baru.

\section{DAFTAR PUSTAKA}

Astuti, D., \& Devitra, J. (2017). Analisis Dan Perancangan Sistem Informasi Simpan Pinjam Pada Koperasi Pegawai Negeri Iain Sultan Thaha Saifuddin Jambi. Manajemen Sistem Informasi. https://doi.org/http://dx.doi.org/10.11591/ju rnalmsi.v12i4.xxxx

Fuad, M. (2015). Perancangan Sistem Informasi Simpan Pinjam Pada Koperasi "KOPITAMA" Depok. UG Jurnal.

Prasojo, M. (2011). Pengantar Sistem Informasi Manajemen . bandung: CV. Remadja Karya.

Samsudin, M., Abdurahman, M., \& Abdullah, M. H. (2019). Sistem Informasi Pengkreditan Nasabah Pada Koperasi Simpan Pinjam Sejahtera Baru Kota Ternate Berbasis Web. Jurnal Ilmiah ILKOMINFO - Ilmu Komputer \& Informatika. https://doi.org/10.47324/ilkominfo.v2i1.16

Satzinger, J. W., Jackson, R. B., Burd, S. D. (n.d.). System Analysis and Design in A Changing World. USA: Cengage Learning.

Subyantoro, A. (2015). Manajemen Koperasi. Yogyakarta: Gosyen Publishing.

Sugiyono. (2016). Metode Penelitian Kuantitatif, Kualitatif dan $R \& D$. Bandung: PT Alfabet.

Sutabri, T. (2012). Analisis Sistem Informasi. Yogyakarta: Andi.

Tyoso, J. S. P. (2016). Sistem Informasi Manajemen. Yogyakarta: DeePublish.

Wati, H. K., \& Siahaan, K. (2017). Analisis Dan Perancangan Sistem Informasi Koperasi Simpan Pinjam Berbasis Web Pada Mts Negeri Talang Bakung Kota Jambi. Jurnal Manajemen Sistem Informasi.

Widiati, W. (2017). Aplikasi Pengolahan Data Koperasi Simpan Pinjam Untuk Meningkatkan Pelayanan Koperasi. IJSE Indonesian Journal on Software Engineering. 